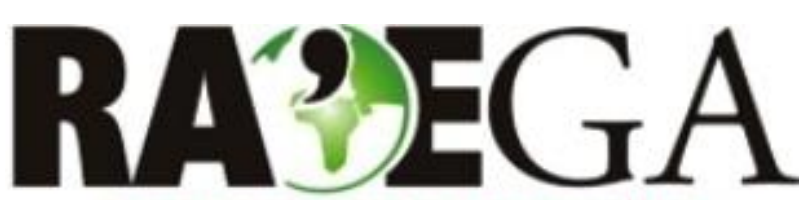

O ESPACYO GEOGRAFICO EM ANÁLISE

\title{
HISTÓRIA DA GEOGRAFIA AGRÁRIA BRASILEIRA: NILO BERNARDES
}

\section{HISTORY OF BRAZILIAN RURAL GEOGRAPHY: NILO BERNARDES}

\author{
Flamarion Dutra Alves \\ Universidade Federal de Alfenas - UNIFAL \\ Alfenas, MG, Brasil \\ e-mail:dutrasm@yahoo.com.br
}

Recebido em: 20/03/2015

Aceito em: 11/04/2016

\section{Resumo}

O presente estudo faz considerações sobre a obra do geógrafo Nilo Bernardes (19221991) que durante mais de 30 anos trabalhou no Instituto Brasileiro de Geografia e Estatística (IBGE) desenvolvendo pesquisas sobre a geografia agrária, colonização, estrutura fundiária e pensamento geográfico. A análise da trajetória geográfica de Nilo Bernardes parte dos livros e artigos publicados pelo autor e entrevista de outros geógrafos acerca da importância e história do pesquisador, sua produção vasta permitiu realizar uma análise densa de seu pensamento, das influências recebidas a suas influências transmitidas. O material obtido e sistematizado auxiliou para delinear as principais características teórico-metodológica de Nilo Bernardes, tendo forte influência do alemão Leo Waibel nas suas pesquisas e adoção de métodos e técnicas oriundos da geografia francesa de Paul Vidal de La Blache, em síntese, a contribuição da trajetória geográfica de Nilo Bernardes vai além da descrição das regiões visitadas, mas de uma análise profunda das relações do homem com o meio, uma visão do planejamento regional associada as questões naturais e humanas. Portanto, esse artigo tem como principal finalidade resgatar a memória e as ideias de Nilo Bernardes, um grande geógrafo do IBGE e da geografia brasileira que contribuiu para a consolidação da ciência geográfica.

Palavras-chave: História do Pensamento Geográfico, IBGE, Geografia Rural, Epistemologia.

\begin{abstract}
This study raises questions regarding the work of geographer Nile Bernardes (19221991) who for over 30 years worked at the Brazilian Institute of Geography and Statistics (IBGE) conducting research on rural geography, colonization, land structure and geographical thought. The analysis of the geographical trajectory of Nilo Bernardes of the books and articles published by the author and interviewing other geographers
\end{abstract}


about the importance and history of the researcher, his vast production helped achieve a dense analysis of his thought, the influences received their influences transmitted. The material obtained and systematized helped to outline the main theoretical and methodological characteristics of Nilo Bernardes, with strong influence of German Leo Waibel in their research and adoption of methods and techniques derived from the French geography of Paul Vidal de la Blache, in summary, the contribution the geographical trajectory of Nilo Bernardes goes beyond the description of the regions visited, but a thorough analysis of man's relationship with the environment, a vision of regional planning associated natural and human issues. Therefore, this article is primarily intended to rescue the memory and the ideas of Nilo Bernardes, a great geographer IBGE and Brazilian geography that contributed to the consolidation of geographical science.

Keywords: History of Geographical Thought, IBGE, Rural Geography, Epistemology.

\section{INTRODUÇÃO}

Os estudos sobre a história do pensamento geográfico são tão importantes quanto os estudos empíricos que lidam com dados primários e o trabalho de campo, pois elucidam questões já trabalhadas por geógrafos e que podem dar subsídios a pesquisas atuais, desenvolvendo parâmetros, apontando erros e acertos, desvendando as origens do pensamento de autores, escolas, instituições e grupos.

A geografia agrária tem mostrado uma diversidade de temas explorados ao longo dos oitenta anos de geografia universitária no Brasil, diferentes concepções teóricas, metodologias e técnicas variadas para explicar a dinâmica dos espaços agrários. As pesquisas de Alves (2010), Ferreira (2001) e Suzuki (2007), por exemplo, demonstram a heterogeneidade de concepções existentes na geografia agrária brasileira, ideias que acompanharam a evolução do pensamento geográfico, as tradições francesas, a revolução teórico-quantitativa, renovação crítica, percepção e geografia até a pluralidade metodológica a partir da década de 2000 (ALVES, 2010).

Dentro desse contexto histórico-geográfico, o Instituto Brasileiro de Geografia e Estatística (IBGE) é uma instituição importante na formação da trajetória da geografia brasileira, tendo sua origem em 1938, mas com suas bases no Conselho Nacional de Geografia (CNG) criado em 1933, contando com a presença de inúmeros geógrafos brasileiros e estrangeiros. Nesse 
sentido, o objeto de análise nesse artigo é a contribuição deixada pelo geógrafo pesquisador do IBGE Nilo Bernardes (1922-1991) (Foto 1).

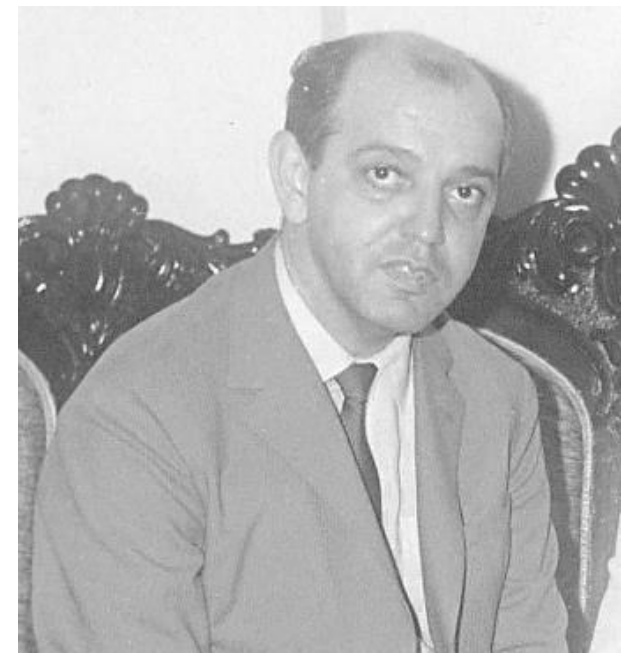

Figura 1 - Foto de Nilo Bernardes.

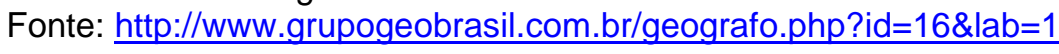

Nilo Bernardes nascido em 1992 natural de Lavrinhas, interior de São Paulo, começou a trabalhar no IBGE em 1944 e se aposentou em 1987, foi casado com a geógrafa também do IBGE, Lysia Bernardes, onde moraram no bairro das Laranjeiras no Rio de Janeiro. Durante sua trajetória profissional na Geografia atuou em algumas instituições como o Instituto Panamericano de Geografia e História, lecionou na Pontifícia Universidade Católica do Rio de Janeiro e também no Colégio Pedro II. Auxiliou na criação do curso de Geografia na Universidade de Brasília em 1967, juntamente com Aziz Ab'Saber, Nice Lecocq Muller, Maria do Carmo Galvão e Carlos de Castro Botelho.

As áreas de pesquisa estiveram ligadas a geografia humana, em especial a geografia agrária e questões ligadas a colonização e estrutura fundiária. A síntese de seu caminho na geografia foram sete livros publicados, catorze capítulos de livro, cinquenta e dois artigos em revistas, atlas e livros didáticos. Nilo Bernardes falece em 1991 num acidente rodoviário no trajeto Rio de Janeiro à Búzios com sua esposa Lysia Bernardes (ALMEIDA, 2000).

Desse modo, o objetivo do artigo é resgatar a contribuição do geógrafo Nilo Bernardes para a construção da geografia agrária no Brasil, verificando as 
principais influências teórico-metodológicas em sua obra, assim como, caracterizar as temáticas desenvolvidas ao longo dos mais de trinta anos de atuação no Instituto Brasileiro de Geografia e Estatística, e por fim, analisar os métodos, técnicas e conceitos abordados pelo autor, fundamentando sua base epistemológica na geografia agrária.

\section{MATERIAIS E MÉTODOS}

Evidenciar o pensamento de um autor e seu legado a uma ciência requer cuidado quanto às fontes consultadas, métodos e técnicas adotadas, a fim de transparecer com maior fidelidade as ideias e o conteúdo publicado pelo autor. Fazer a contextualização da obra com a realidade da época sempre se faz necessário, com a intenção de mostrar as necessidades daquele momento, técnicas de pesquisas existentes, paradigma e sistema político vigente.

No trabalho de Alves (2010) alguns geógrafos que pesquisaram o espaço agrário tiveram grande destaque devido ao número de artigos publicados em diversos periódicos e por ser referências para demais estudos no campo da geografia agrária. Por este motivo, o resgate de parte da obra de Nilo Bernardes é importante para a investigação da história da geografia agrária brasileira.

Desse modo, adotamos os procedimentos metodológicos em Alves (2010) sobre a história da geografia agrária, analisando a obra de Nilo Bernardes a partir do período denominado Clássico da geografia, no qual teve a primeira geração de geógrafos no Brasil, conforme aponta o estudo Scarim (2008).

Este período é caracterizado pela forte influência lablacheana na formação dos geógrafos brasileiros, com a vinda de geógrafos da França para a criação da geografia acadêmica no Brasil. A respeito da geografia francesa empregada nos estudos agrários Alves (2012b, p.1) afirma:

O objetivo é analisar os elementos qualitativos, como gêneros de vida, modos de vida, habitat e os elementos que compõem a paisagem. A geografia da agricultura se atrela somente as questões da produção agrícola em questão, assim, seria um 
ramo da geografia econômica que trata da produção agrícola. (ALVES, 2012b, p.1)

Nesse período, o Brasil passava por grandes mudanças de ordem político-econômica. Desde a fundação do IBGE até os governos por Getúlio Vargas, a importância de se entender e caracterizar o território nacional estava em pauta, por esse motivo, entre 1930 e 1960 foi marcado pelos estudos regionais, a interação homem-meio e as técnicas descritivas da paisagem, conforme aponta Alves (2012a) o importante era a caracterização e descrição do território nacional

\begin{abstract}
A forte influência francesa na geografia brasileira delineou o início dos aportes teóricos nos estudos rurais nas décadas de 1940 e 1950. As pesquisas regionais apoiadas no empirismo, técnicas de observação e descrição das paisagens determinaram o método predominante na geografia agrária brasileira (ALVES, 2012a, p.318).
\end{abstract}

Nas décadas de 1960 a 1980, a geografia passa a adotar métodos e técnicas condizentes com um pensamento neopositivista calcados na quantificação e modelos espaciais, num período político marcado pela ditadura militar, no qual o IBGE fez uso desse princípio tecnocrata sob viés do planejamento, conforme aponta a tese de Almeida (2000). Assim, é a partir desse contexto, que se constrói a obra de Nilo Bernardes, sob vários espectros metodológicos e contextos políticos.

A análise do pensamento de Nilo Bernardes realizada na pesquisa se fundamenta, basicamente, a partir de suas publicações em revistas científicas e livros. O Boletim Geográfico e a Revista Brasileira de Geografia, ambas do IBGE, foram os veículos de maior destaque e importância em sua trajetória (Quadro 1).

Quadro 1 - Obras consultadas sobre o pensamento de Nilo Bernardes.

\begin{tabular}{|c|c|c|}
\hline Ano & Título & Tipo de publicação \\
\hline 1950 & $\begin{array}{c}\text { A colonização no município de Santa Rosa, Estado do } \\
\text { Rio Grande do Sul }\end{array}$ & $\begin{array}{c}\text { Revista Brasileira de } \\
\text { Geografia }\end{array}$ \\
\hline 1950 & A pesca no litoral do Rio de Janeiro & $\begin{array}{c}\text { Revista Brasileira de } \\
\text { Geografia }\end{array}$ \\
\hline 1951 & $\begin{array}{c}\text { Notas sobre a distribuição da produção de carnes e } \\
\text { banha no Rio Grande do Sul }\end{array}$ & \begin{tabular}{c} 
Boletim Geográfico \\
\hline
\end{tabular} \\
\hline
\end{tabular}

R. Ra'e Ga - Curitiba, v. 36, p 69 -91 , Abr/2016 
ALVES, F. D.

HISTÓRIA DA GEOGRAFIA AGRÁRIA BRASILEIRA: NILO BERNARDES

\begin{tabular}{|c|c|c|}
\hline 1952 & A colonização européia no Sul do Brasil & Boletim Geográfico \\
\hline 1952 & Leo Waibel & $\begin{array}{l}\text { Revista Brasileira de } \\
\text { Geografia }\end{array}$ \\
\hline 1952 & Expansão do Povoamento no Estado do Paraná & $\begin{array}{c}\text { Revista Brasileira de } \\
\text { Geografia }\end{array}$ \\
\hline 1958 & $\begin{array}{l}\text { Vale do Paraíba, Serra da Mantiqueira e arredores de } \\
\text { São Paulo }\end{array}$ & Livro \\
\hline 1958 & A ocupação humana no Baixo Cassiporé & Anais \\
\hline 1959 & $\begin{array}{l}\text { Notas sobre ocupação humana da montanha no } \\
\text { Distrito Federal }\end{array}$ & $\begin{array}{l}\text { Revista Brasileira de } \\
\text { Geografia }\end{array}$ \\
\hline 1961 & $\begin{array}{c}\text { Características gerais de agricultura brasileira no } \\
\text { século XX }\end{array}$ & $\begin{array}{l}\text { Revista Brasileira de } \\
\text { Geografia }\end{array}$ \\
\hline $\begin{array}{l}1962 \\
1963\end{array}$ & $\begin{array}{l}\text { Bases geográficas do povoamento do Estado do Rio } \\
\text { Grande do Sul }\end{array}$ & Boletim Geográfico \\
\hline 1963 & O problema do estudo do habitat rural no Brasil & Boletim Geográfico \\
\hline 1966 & O espaço econômico brasileiro & Livro \\
\hline 1967 & Condições geográficas da colonização em Alagoas & $\begin{array}{l}\text { Revista Brasileira de } \\
\text { Geografia }\end{array}$ \\
\hline 1969 & Geografia e desenvolvimento & Boletim Geográfico \\
\hline 1969 & A geografia e o planejamento regional & Livro \\
\hline 1970 & Minas Gerais: terra e povo & Livro \\
\hline 1976 & $\begin{array}{c}\text { Considerations on regional development and the } \\
\text { spatial location of economic activities in the } \\
\text { developing countries }\end{array}$ & Geoforum \\
\hline 1978 & $\begin{array}{c}\text { Sobre diversificação e sua medida aplicada à } \\
\text { geografia agrária }\end{array}$ & Geografia (Rio Claro) \\
\hline 1982 & O pensamento geográfico tradicional & $\begin{array}{l}\text { Revista Brasileira de } \\
\text { Geografia }\end{array}$ \\
\hline 1982 & $\begin{array}{c}\text { A influência estrangeira no desenvolvimento da } \\
\text { Geografia no Brasil }\end{array}$ & $\begin{array}{l}\text { Revista Brasileira de } \\
\text { Geografia }\end{array}$ \\
\hline 1997 & $\begin{array}{l}\text { Bases geográficas do povoamento do Estado do Rio } \\
\text { Grande do Sul }\end{array}$ & Livro \\
\hline 1999 & As caatingas & Estudos Avançados \\
\hline
\end{tabular}

A análise de conteúdo feita das obras consultadas parte dos pressupostos que caracterizam a base teórico-metodológica do autor: conceitos trabalhados, teorias utilizadas, técnicas de pesquisa empregadas, método de análise e objeto geográfico. Dessa maneira, os temas abordados na pesquisa referente a obra de Nilo Bernardes, seguem os apontamentos de Etges (2000) ao tratar da relação do autor com a influência herdada por Leo Waibel "Nilo Bernardes, também teve como centro de suas atenções a questão da colonização e da ocupação das terras no sul do país" (ETGES, 2000, p.167). 
Outro ponto da análise refere-se ao método indutivo-regional-descritivo adotado pela geração de geógrafos entre as décadas de 1930 a 1970, a partir desse aspecto será feita uma relação da produção científica do autor com essa abordagem geográfica francesa lablacheana, tentando averiguar as interfaces do pensamento francês na trajetória de Nilo Bernardes.

Convém destacar, que esse artigo visa dar continuidade a relação de geógrafos que contribuíram para a geografia agrária brasileira (ALVES e FERREIRA, 2011).

\title{
2.1 Características do método regional
}

Será exposto brevemente as definições do método regional, originário nas pesquisas de Paul Vidal de La Blache e incorporadas pelos geógrafos no Brasil e amplamente utilizado entre as décadas de 1930 a 1970 na geografia agrária brasileira.

Os principais pressupostos teóricos de Paul Vidal de La Blache a respeito dos estudos regionais centram-se na investigação dos habitats, gêneros de vida e a relação do homem com o meio. A partir desses elementos se caracterizam e se diferem as paisagens e a formação das regiões, por isso Vidal de La Blache (1954) aponta algumas questões para a pesquisa das regiões:

\begin{abstract}
O geógrafo não pode contentar-se com os números publicados nas estatísticas oficiais. É necessário que lhes junte os dados que diversas fontes lhe podem fornecer, uma vez que se trata de determinar, pela comparação dos espaços disponíveis e dos efetivos, até que ponto está realizada, atualmente a ocupação da Terra pelo Homem. Todas as partes da superfície terrestre devem ser consideradas, o que aliás, apesar da insuficiência de certas informações, não tem hoje nada de quimérico. Só o conjunto, precisamente pelas diferenças, contrastes e anomalias que permite descobrir, assume pleno significado. (VIDAL DE LA BLACHE, 1954, p.49).
\end{abstract}

Essas análises em conjunto entre paisagens dá o caráter regional para as pesquisas elaboradas por Vidal de La Blache, conforme aponta Hissa (2005, p.13) “(...) a esse real de Paul Vidal de La Blache é endereçado um conjunto de combinações entre fenômenos (...) à geografia caberia a análise desses 
elementos e de suas combinações. À geografia caberia a caracterização das regiões, sob a referência dos mesmos fenômenos".

Numa visão semelhante Daniel Faucher (1963) ao tratar dos métodos em geografia agrária destacou o processo gerador da paisagem agrária e como se deve entender essa construção de pensamento:

\begin{abstract}
Os sistemas agrícolas, ajustados aos modos de vida e às condições geográficas, são geradores da maioria dos fenômenos por onde se caracteriza, num dado lugar, a paisagem agrária. [...] A influência dos sistemas agrícolas sobre o habitat não é menos evidente. A dispersão ou a concentração da população podem ser criadas ou favorecidas por fatores físicos, às vezes por circunstâncias históricas. (FAUCHER, 1963, p.186-187).
\end{abstract}

A respeito da distinção dos métodos usados nos estudos rurais Faucher (1963) distingue os procedimentos e elementos a serem pesquisados nos diferentes ramos da geografia rural (econômica, agrária e da agricultura). $\mathrm{Na}$ geografia econômica, tem como objeto de análise "o estudo da repartição das culturas do mundo, o conhecimento de seu volume, de seu emprego, de sua circulação" (1963, p.185), e tem como fundamento básico a estatística, por este motivo é uma geografia quantitativa.

A geografia agrária "visa as formas de atividades que criam as culturas e todos trabalhos inscritos no meio geográfico em função desta atividade" (FAUCHER, 1963, p.185). O objetivo é analisar os elementos qualitativos, como gêneros de vida, modos de vida, habitat e os elementos que compõem a paisagem. A geografia da agricultura se atrela somente as questões da produção agrícola em questão, assim, seria um ramo da geografia econômica que trata da produção agrícola.

Na perspectiva de Haesbaert (2012) Vidal de La Blache vai além dos limites naturais ou humanos da região, entretanto a ideia do método regional associado somente aos limites físicos é deficiente:

Em síntese, em relação a abordagem regional, Vidal é muito mais do que o Vidal "localista" do pays (aliás, ele chega a afirmar que pays não é o mesmo que região, e não recomenda o estudo geográfico centrado nessas unidades, pois elas ocultariam as relações mais gerais), da região de limites bem definidos (pois apela até mesmo à área de influência bancária

R. Ra'e Ga - Curitiba, v. 36, p 69 -91 , Abr/2016 
para sustentar a relatividade dos limites regionais), restrita a uma determinada escala (por diversas vezes ele indica que um Estado ou um continente podem ser vistos como regiões) e fundada sobre pressupostos naturais ou agrários. (HAESBAERT, 2012, p.197-198).

Portanto, o método regional é mais abrangente que a definição natural do espaço, mas deve ser interpretado pela relação homem e meio, aspectos interligados em conjunto e sistemas, propósitos humanos sob as características naturais.

\section{RESULTADOS E DISCUSSÃO}

\subsection{Geografia agrária regional de nilo bernardes}

O geógrafo Nilo Bernardes atravessou mais de trinta anos de sua vida dedicando-se a geografia e as pesquisas desenvolvidas no IBGE. Casado com Lysia Bernardes, também geógrafa do IBGE, promoveu inúmeros trabalhos de campo, expedições, monografias regionais, regionalizações e estudos sobre a geografia agrária.

Sob forte influência da geografia regional francesa e dos aportes teóricos de Leo Waibel, a geografia agrária de Nilo Bernardes segue os caminhos das regiões ocupadas por imigrantes, os sistemas agrícolas desenvolvidos nas colônias, a relação do homem com seu habitat rural, a formação dos gêneros de vida no processo histórico de ocupação e a organização das paisagens culturais.

A base conceitual apoiada em Leo Waibel pode ser verificada na pesquisa realizada nas colônias no município de Santa Rosa - RS, a relação da paisagem natural e cultural:

A paisagem cultural conserva um aspecto pioneiro estacionário, se assim podemos nos expressar, o que é estranho, pois passaram-se vinte anos do início da ocupação da região, e trata-se de um município dos mais procurados pelas correntes povoadoras recentes. Devemos considerar, entretanto, que a topografia muito acidentada e o solo muito pedroso (BERNARDES, 1950, p.387). 
Aliada a paisagem cultural estavam às atividades econômicas desenvolvidas pelos agricultores, assim, Bernardes (1951) analisou a produção de carne e banha no Rio Grande do Sul, baseado nos dados do Boletim Estatístico do $R S$, inferindo relações com as zonas de pecuária bovina (grande propriedade) e zonas de produção familiar (pequenas propriedades), ou seja, a produção de carne advém dos municípios que apresentam grandes propriedades localizadas ao sul do Estado, na qual a imigração não teve participação. Porém, na zona de imigração (alemães e italianos), ao norte do Estado, tem-se grande parcela na produção de banha, pois a criação de suínos está presente, inclusive para a atividade industrial desse produto.

Nota-se as várias relações que Nilo Bernardes fazia sobre o espaço agrário entre estrutura fundiária, colonização, tipos de estabelecimentos, atividades agropecuárias e atividades urbanas.

A imigração foi tema nos trabalhos de Nilo Bernardes (1952a, 1952b), na qual detalhou a ocupação dos colonos europeus na região sul do Brasil. A importância para a agricultura, principalmente a de gêneros alimentícios e no desenvolvimento das cidades, atrelado a dinâmica fisiográfica das regiões:

\footnotetext{
Grande prosperidade alcançaram as colônias riograndenses desta fase. Abstraindo-se pequenos núcleos paranaenses já fundados, os italianos no Rio Grande do Sul foram os primeiros europeus a ocupar terras de pinhais. Foram localizados "acima da serra" na borda do planalto em altitudes variando de 700 a 800 metros (BERNARDES, 1952, p.95).
}

Sob influência francesa, Nilo Bernardes (1963b) faz um resgate teórico do conceito de habitat, termo muito utilizado nos trabalhos de geografia agrária, que classifica como as formas de povoamento estão organizadas, ou seja, são classificadas como dispersas, intermediárias, concentração, espontâneas e planejadas. Entretanto, existem zonas de transição entre cada uma delas, pois a estrutura agrária brasileira é altamente concentrada, e às vezes a agricultura de cunho familiar esta aglomerada próxima às lavouras monocultoras, nas quais o habitat é extremamente disperso.

A respeito do termo habitat rural, Bernardes (1963b) lembra que este conceito é advindo da escola francesa, que representa a dinamicidade da 
paisagem, sua expansão. Todavia, o autor considera a terminologia mais adequada para descrever a questão do povoamento e sua dinâmica, a expressão da geografia portuguesa, denominada "Formas de Povoamento", na qual concebe melhor a organização da paisagem agrária.

Em um estudo para exemplificar os gêneros de vida, Bernardes (1959) analisa a paisagem cultural estabelecida com o desenvolvimento da agricultura nas montanhas do Distrito Federal, modificando os gêneros de vida presentes.

Ainda sobre a colonização, Nilo Bernardes (1967) estudou este processo no Estado de Alagoas, indicando alguns apontamentos demográficos servindo de base para projetos de reforma agrária "[...] em se tratando de região onde as densidades demográficas são razoavelmente elevadas, a colonização é, na realidade, um esforço de reforma agrária, em domínio de estruturas defeituosas, tema que se impõe com atualidade constante". (BERNARDES, 1967, p.65).

Este estudo com cunho descritivo, o autor focalizou três variáveis de cada colônia, o elemento físico, ou seja, as condições do sítio, sua topografia, drenagem, solos e vegetação. O estudo da posição em relação às rodovias, proximidade de grandes centros e climas do nordeste, por fim, o elemento humano, no qual esta ligada a população, condições de educação, saúde, serviços em gerais, bem como o nível técnico para a produção agrícola.

Baseado nesses três elementos, Nilo Bernardes (1967) verificou seis colônias e apontou para algumas considerações sobre estrutura fundiária, sistemas produtivos, habitat rural e elemento humano:

[...] o problema não é somente determinar e implantar o
tamanho mínimo de parcela essencial à manutenção de uma
família média em padrão econômico e cultural decente em
determinadas condições de utilização da terra (conforme Leo
Waibel: o conceito de minimale Ackernahrung). Comporta
também prever a prazo relativamente curto os efeitos da
evolução fundiária. (BERNARDES, 1967, p.81).

Nilo Bernardes (1961) faz uma análise apurada das características gerais da agricultura brasileira no século $X X$, tanto sob o enfoque agrícola e da 
produção, como da estrutura fundiária e condições socioculturais. Baseado no Censo Agrícola de 1950 elaborou cartogramas com isolinhas da estrutura fundiária brasileira (Figura 2), além de mapas sobre a utilização da terra, localização de tratores e arados. Estes dados serviram para mostrar a desigualdade existente no campo brasileiro, nos aspectos econômicos e sociais. A cerca deste assunto, Bernardes (1961) utilizou referências de Caio Prado Júnior para retratar o contraste existente no cenário agrário brasileiro:

\begin{abstract}
A quantos se têm interessado pelos problemas rurais brasileiros não escapou a forte persistência na estrutura agrária das características coloniais de origem. Persistência que se faz sentir em um tríplice aspecto: tanto na organização fundiária e nos regimes de exploração, de tão profundas conseqüências sociais, quanto nas modalidades principais de utilização da terra. (BERNARDES, 1961, p.381).
\end{abstract}

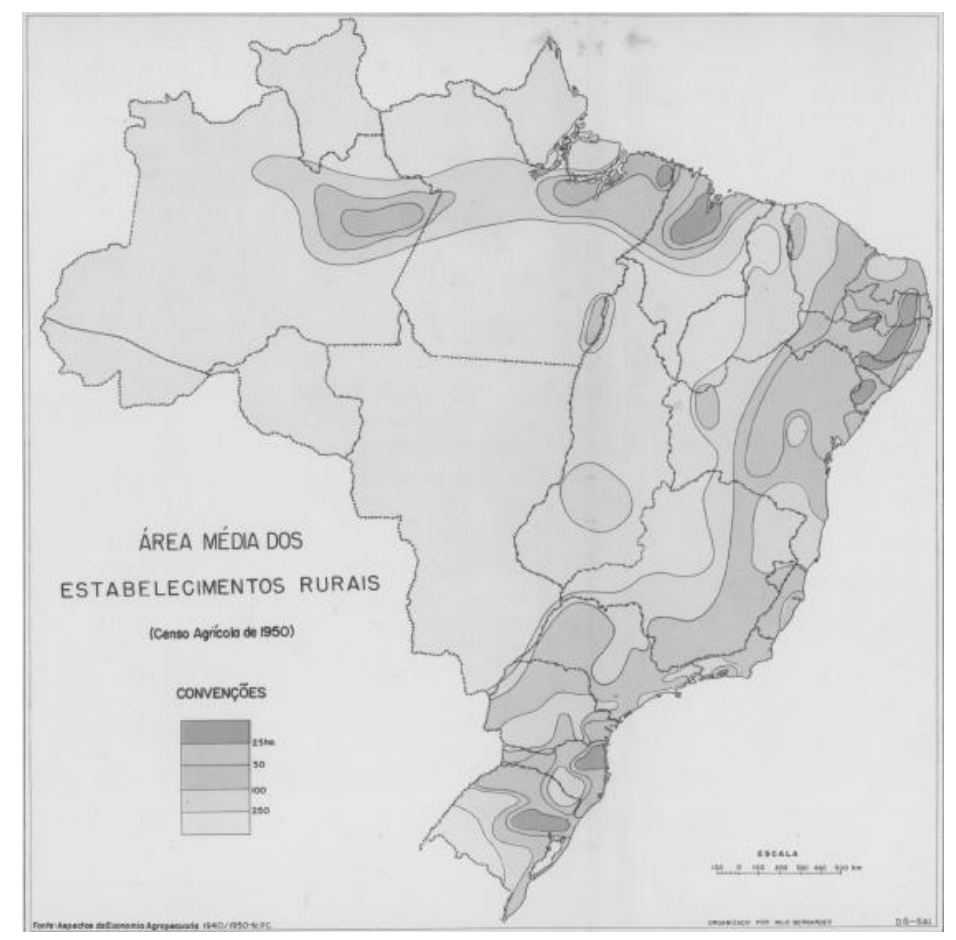

Figura 2 - Mapa da área média dos estabelecimentos rurais no Brasil, 1950. Fonte: Bernardes (1961, p.368).

Nilo Bernardes $(1962,1963 a)$ analisa a relação da vegetação com o processo de ocupação nas regiões de Planalto e de Campos no Rio Grande do Sul e a formação dos habitat rural e as aglomerações urbanas. Com enfoque 
regional e com caráter possibilista, entende que as condições naturais deram origem as atividades agropecuárias desenvolvidas, além da formação das estruturas econômico-sociais. Porém, com o passar do tempo às condições naturais não foram predominantes para tais organizações distintas, no Estado do Rio Grande do Sul:

Esta justaposição de duas estruturas econômico-sociais tão distintas, com limites tão rígidos, mantém-se até os dias atuais sem que se verifique uma interpenetração originando área de transição. Se a distribuição da vegetação causou esta dualidade, sua persistência só se explica pela interferência permanente dos fatores culturais. (BERNARDES, 1962, p.620).

A relação desses elementos era a chave metodológica dos geógrafos do IBGE para descrever a ocupação e organização humana no território. Nilo Bernardes (1970) faz um estudo sobre a fisionomia da terra e a ocupação humana em Minas Gerais, o autor faz uma divisão regional do estado e correlaciona as variáveis "É fácil notar que o Triângulo Mineiro é uma região onde os quadros naturais são típicos do Centro-Oeste, mas onde os impulsos que se fazem sentir na ocupação humana refletem a influência direta do Sudeste" (BERNARDES, 1970, p.9)

Outro elemento metodológico encontrado na investigação sobre o estado de Minas Gerais é o método comparativo, muito peculiar da geografia clássica, onde Bernardes (1970) descreve os aspectos físicos da região do Rio São Francisco e sua ocupação humana: Os solos destas planícies vazantes não têm, porém, fertilidade
análoga à que existe junto a outros grandes rios como o Nilo.
As margens do São Francisco não condensam população
agrícola numerosa. O delgado manto de sedimentos das
margens do rio é muito arenoso, nada fértil e pouco próprio
para cultivos tradicionais. Paradoxalmente, a população prefere
as partes afastadas do rio, cujas margens imediatas, onde o
chão é muito arenoso ou pulverulento, apresentam,
frequentemente, um ar de grande desolação. (BERNANRDES,
1970, p.7-8).

O rigor metodológico na obra de Nilo Bernardes proporcionou avanços e contribuições para a ciência geográfica. Dominando 0 assunto das colonizações pelos imigrantes no sul do Brasil, realizou diversas expedições ao 
Rio Grande do Sul, dando sustentação para realizar uma regionalização das zonas fisiográficas (Figura 3).

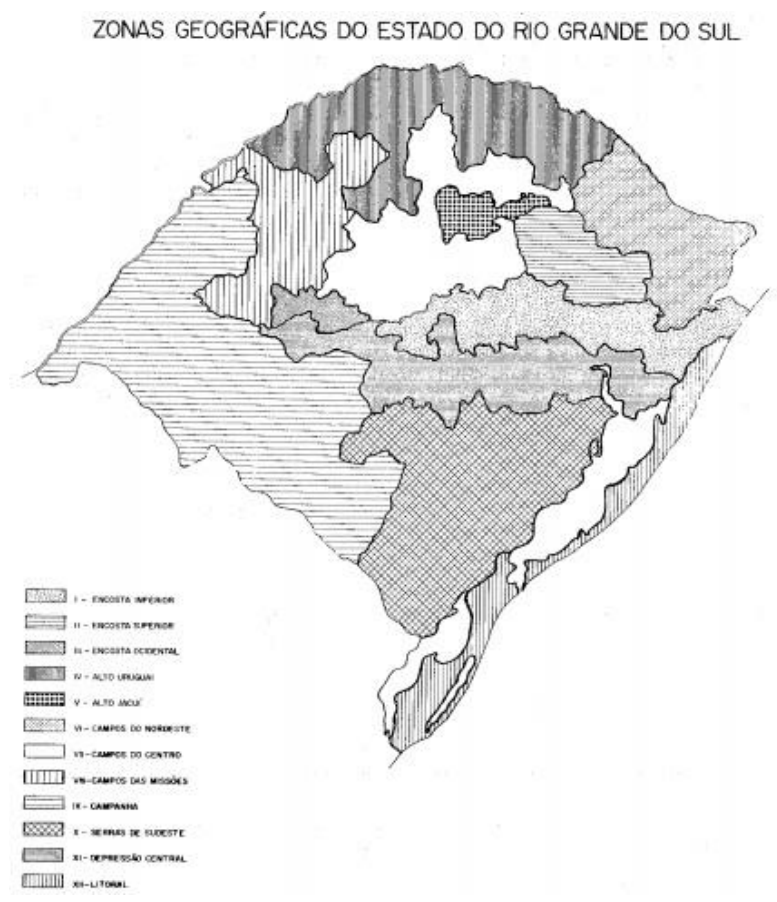

Figura 3 - Regionalização fisiográfica do Rio Grande do Sul. Fonte: Bernardes (1963a).

Nilo Bernardes (1963a) não classificou somente as zonas físicas (geográficas) com o intuito de diferenciá-las, mas de comparar e correlacionar com a dinâmica populacional e os aspectos econômicos que forma as diferentes paisagens culturais:

\begin{abstract}
Ainda que se considere o fato de, em muitos lugares, os campos não serem apropriados ao cultivo, o que conduziu à permanência dessa separação tão rígida das duas formas econômicas não foi a imposição dos fatores naturais, mas sim a persistência da tradição cultural: um conformismo condicionado pelos ambientes geográficos diversos e não uma forma de determinismo (BERNARDES, 1963a, p.13).
\end{abstract}

Sobre o mapa das zonas geográficas no Rio Grande do Sul, Mesquita (1984) destaca a importância do esforço metodológico e classificatório feito por Nilo Bernardes:

[...] o trabalho representou uma inovação do ponto de vista metodológico ao descartar a dicotomia região natural

R. Ra'e Ga - Curitiba, v. 36, p $69-91$, Abr/2016 
ALVES, F. D.

HISTÓRIA DA GEOGRAFIA AGRÁRIA BRASILEIRA: NILO BERNARDES

totalmente dissociada de região cultural ou humana. Esse aspecto inovador é expresso tanto no esforço de estabelecer correlações entre os vários aspectos físicos e os humanos como no já mencionado abandono da separação entre região natural e região humana, ainda que a própria divisão regional sugerida esteja fortemente embasada naquela. (1984, p.107).

De certa forma, as décadas de 1950 e 1960 mostraram uma tendência aos estudos regionais, de caráter exploratório e monográfico nas zonas onde teve colonização por imigrantes europeus, fortemente atrelados aos conceitos lablacheanos de gênero de vida e habitat rural, os métodos descritivos e comparativos, além dos procedimentos da pesquisa baseados no tripé quadro natural - quadro humano - quadro histórico. Somado aos elementos metodológicos franceses vem à contribuição de Leo Waibel, o rigor da pesquisa, o uso da estatística, a adoção dos conceitos de paisagem cultural e paisagem natural, e por fim, a criação do conceito de Formas de Povoamento, sendo um híbrido de gênero de vida e das paisagens cultural. Este conceito foi fruto de suas pesquisas empíricas ao longo dos anos acerca das regiões colonizadas.

Assim como o movimento de renovação metodológica na geografia, o IBGE passou a adotar técnicas e métodos neopositivistas a partir da década de 1970, com intuito de utilizar os dados censitários, fazer novas regionalizações a partir de uma gama de variáveis, enfim, esse processo de transformação paradigmática entra com menor importância na obra de Nilo Bernardes, mas mostra a diversidade do pensamento do geógrafo, adaptando-se metodologicamente ao contexto político-geográfico da época.

Assim, Nilo Bernardes (1969a) salienta para a mudança de paradigma na ciência geográfica, sendo necessário abandonar "em certa medida, o sentido fundamentalmente ecológico da fase clássica" (p.108) por uma geografia aplicada e prática, servindo os interesses da sociedade e de sua organização e dinâmica:

A idéia fundamental da geografia moderna, repito, é a compreensão das formas de organização do espaço pelos grupos humanos. É a definição do modo como se repartem as atividades de como se enfeixam, se adensam ou se rarefazem 
ALVES, F. D.

HISTÓRIA DA GEOGRAFIA AGRÁRIA BRASILEIRA: NILO BERNARDES

os fluxos da vida de relações. Na formulação dos objetivos da pesquisa assim orientada, variaram as tendências no modo de focalizar o homem geográfico. Estudo do homem, habitante para alguns, do homem produtor, do homem consumidor, para outros. De qualquer modo, trata-se da preocupação pela repartição das funções em um espaço (veja-se aqui o reforço dos velhos princípios de localização e extensão) e dos mecanismos eu elas criam segundo seu arranjo. (BERNARDES, 1969a, p.109).

Uma das obras nesse momento de renovação, Nilo Bernardes (1978) trabalha a noção de diversificação da agricultura baseado em teorias e modelos estatísticos, exemplificando sua utilização em algumas microrregiões. O emprego da curva de Lorenz serviu para sustentar os índices de Ayyar e Shear, que determinaram o grau de diversificação das categorias agrícolas.

Na década de 1980, o autor escreveu artigos a respeito da história da geografia, incluindo a influência estrangeira na formação dos geógrafos brasileiros (1982a, 1982b). A respeito disso, Bernardes (1982b) fala sobre seu mestre Leo Waibel:

\footnotetext{
Combinado seu precoce pendor para a Biogeografia (no Brasil, se dedicou ao estudo da vegetação) com seu entusiasmo pela Geografia Econômica, ele fez avançar muito a pesquisa em Geografia do Povoamento (colonização européia), em problemas da utilização da terra e da organização agrária do território. (BERNARDES, 1982b, p.523).
}

Nilo Bernardes apesar de não ser professor de programas de pósgraduação em geografia, mas ao trabalhar durante décadas no IBGE, auxiliou na formação de vários geógrafos, como Edgar Kuhlmann, Nelson de Castro Senra, Roberto Lobato Corrêa entre outros. Esse último o mais conhecido no meio acadêmico da geografia, no qual lembra os ensinamentos de Nilo e Lysia Bernardes:

No Conselho Nacional de Geografia tive a sorte de trabalhar com dois Geógrafos que tiveram urna importância crucial na minha formação. Com eles aprendi a fazer trabalho de campo, fazer mapas temáticos, conheci uma bibliografia mais especializada a que tive acesso e, que foi importante, recebi deles uma atenção toda especial. São os geógrafos Nilo Bernardes e Lysia Bernardes. (CORRÊA, 1986, p.127)

Dessa forma, Nilo Bernardes passou durante os vários períodos metodológicos da geografia contribuindo com grande primazia para a geografia R. Ra'e Ga - Curitiba, v. 36, p 69 -91 , Abr/2016 
agrária, seja nas descrições e formas de povoamento das colônias europeias no Brasil, seja nos estudos classificatórios e uso de modelos quantitativos ou mesmo em pesquisas da história do pensamento geográfico, o que mostra a pluralidade dos fundamentos teórico-metodológicos do autor.

\section{CONSIDERAÇÕES FINAIS}

A contribuição da obra de Nilo Bernardes ultrapassa os limites da geografia agrária, foi um geógrafo que trabalhou com conceitos de escolas diferentes: francesa de La Blache e dos pressupostos de Leo Waibel, o híbrido alemão e estadunidense.

Os temas pesquisados remontam a colonização européia no Brasil, ou seja, como estavam organizadas ao longo das décadas que se inseriram no território brasileiro, seguindo uma política de planejamento e conhecimento do território nacional proposta pelo Estado aos institutos de pesquisa (IBGE) durante as décadas de 1930 a 1960.

Dessa forma, o pensamento de Nilo Bernardes é um mosaico teóricometodológico demonstrando sua pluralidade, apesar do predomínio das características da geografia clássica (Figura 4). 


\section{SÍNTESE DO PENSAMENTO GEOGRÁFICO DE NILO BERNARDES}

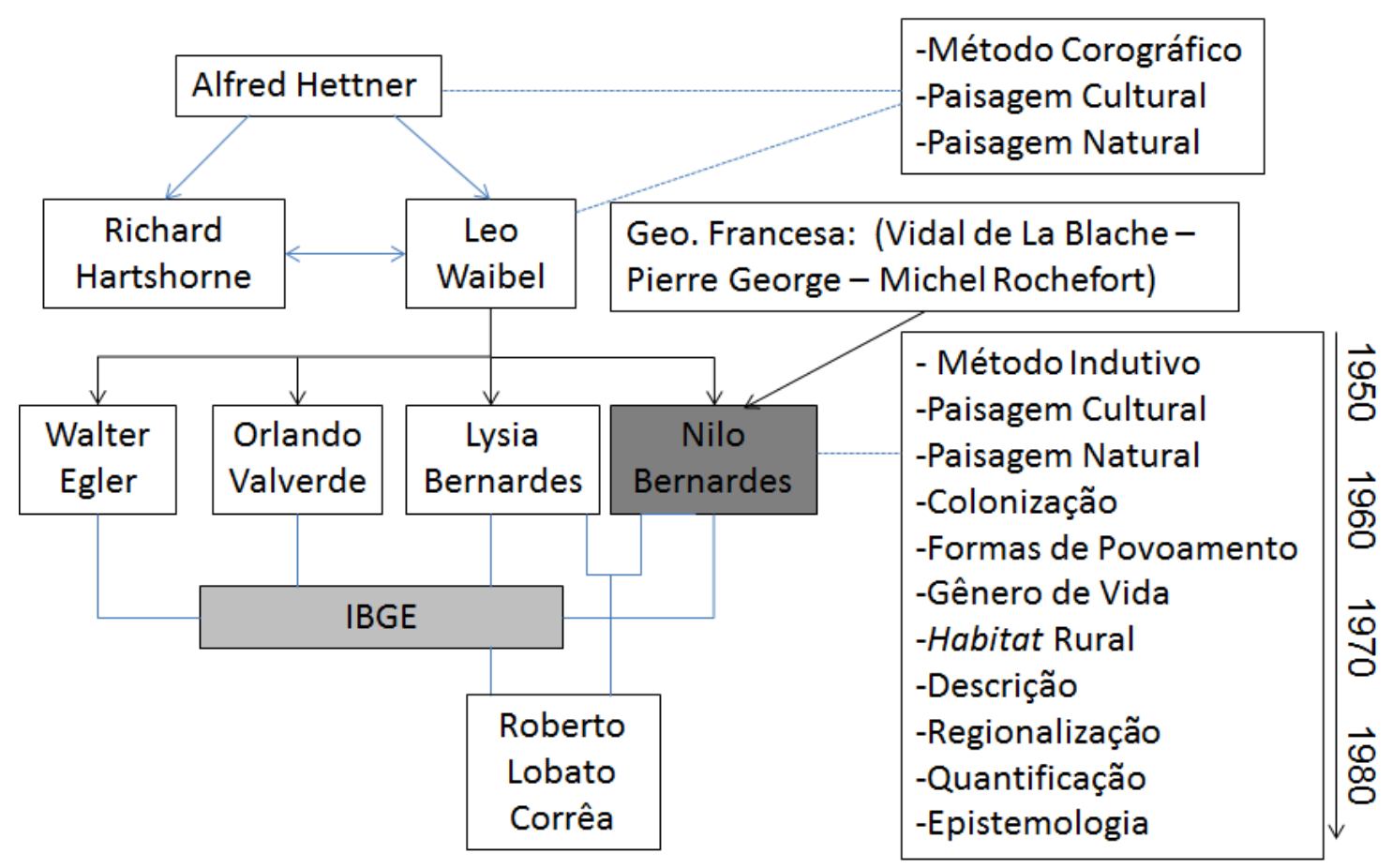

Figura 4 - Síntese da obra e pensamento de Nilo Bernardes.

Elaboração: Flamarion Dutra Alves.

O esquema representa uma síntese do pensamento de Nilo Bernardes, ocultando vários momentos de sua trajetória geográfica. Entretanto, os marcos teóricos são explanados como contribuição de Leo Waibel, com raízes na corografia de Alfred Hettner, assim como as influências lablacheanas nos estudos regionais. Essas duas matrizes do pensamento, sem dúvida, formam como Nilo Bernardes desenvolveu suas pesquisas em geografia agrária.

Essa base diversa que compõe a matriz metodológica de Nilo Bernardes fez com que o pesquisador desenvolvesse investigações capazes de interrelacionar elementos naturais e culturais, associar essas combinações e propor projetos de planejamento e desenvolvimento para diversas regiões do Brasil. Sem dúvida, a influência de várias linhas teórico-metodológicas foi muito rica para o pensamento geográfico do autor, não limitando-o a simples descrições e generalizações, essa pluralidade de ideias deve servir de exemplo para o geógrafo atual desempenhar seu papel na sociedade.

R. Ra'e Ga - Curitiba, v. 36, p $69-91$, Abr/2016 


\section{REFERÊNCIAS}

AB'SABER, Aziz Nacib \& BERNARDES, Nilo. Vale do Paraíba, Serra da Mantiqueira e arredores de São Paulo. São Paulo: CNG, 1958.

ALMEIDA, Roberto Schmidt de. A Geografia e os geógrafos do IBGE no período 1938-1998. Tese de Doutorado (Geografia). Rio de Janeiro: Universidade Federal do Rio de Janeiro, 2000.

ALVES, Flamarion Dutra. Trajetória teórico-metodológica da geografia agrária brasileira: A produção em periódicos científicos de 1939 - 2009. Tese de Doutorado (Geografia - Organização do Espaço). Rio Claro: Universidade Estadual Paulista, 2010.

ALVES, Flamarion Dutra. Abordagens metodológicas da Geografia Agrária clássica brasileira. Caminhos de Geografia, Uberlândia. v.13, n.42, p. 315329, 2012a.

ALVES, Flamarion Dutra. O pensamento francês na geografia rural do Brasil. Confins, Paris. n.16, 2012b. Disponível em: (http://confins.revues.org/7814) . Acesso em: 16, 03, 2015.

ALVES, Flamarion Dutra; FERREIRA, Enéas Rente. História da Geografia Agrária Brasileira: Pierre Monbeig e Leo Waibel. Mercator, Fortaleza, v.10, n.22, p.87-102, 2011.

BECKER, Bertha; BERNARDES, Nilo. Considerations on regional development and the spatial location of economic activities in the developing countries. Geoforum, Londres. v.7, n.3, p.223-232,1976. 
BERNARDES, Nilo. A colonização no município de Santa Rosa, Estado do Rio Grande do Sul. Revista Brasileira de Geografia, Rio de Janeiro. v.12,n.3, p.383-392, 1950.

BERNARDES, Nilo. Notas sobre a distribuição da produção de carnes e banha no Rio Grande do Sul. Boletim Geográfico, Rio de Janeiro. v.9, n.102, p.605609, 1951.

BERNARDES, Nilo. A colonização européia no Sul do Brasil. Boletim Geográfico, Rio de Janeiro. v.10, n.106, p.89-102, $1952 a$.

BERNARDES, Nilo. A colonização européia no Sul do Brasil. Boletim Geográfico, Rio de Janeiro. v.10, n.109, p.442-448, 1952b.

BERNARDES, Nilo. Leo Waibel. Revista Brasileira de Geografia, Rio de Janeiro. v.14, n.2, p.199-201,1952c.

BERNARDES, Nilo. Expansão do Povoamento no Estado do Paraná. Revista Brasileira de Geografia, Rio de Janeiro. n.14, n.1, p. 53-78, 1952d.

BERNARDES, Nilo. A ocupação humana no Baixo Cassiporé. XIII Assembléia da AGB. Santa Maria, 1958.

BERNARDES, Nilo. Notas sobre ocupação humana da montanha no Distrito Federal. Revista Brasileira de Geografia, Rio de Janeiro. v.21, n.3, p.363$388,1959$.

BERNARDES, Nilo. Características gerais de agricultura brasileira no século XX. Revista Brasileira de Geografia, Rio de Janeiro. v.23, n.2, p.363-420, 1961. 
BERNARDES, Nilo. Bases geográficas do povoamento do Estado do Rio Grande do Sul. Boletim Geográfico, Rio de Janeiro. v.20, n.171, p. p.587-620, 1962.

BERNARDES, Nilo. Bases geográficas do povoamento do Estado do Rio Grande do Sul. Boletim Geográfico, Rio de Janeiro. v.21, n.172, p.3-29, 1963a.

BERNARDES, Nilo. O problema do estudo do habitat rural no Brasil. Boletim Geográfico, Rio de Janeiro. v.22, n.176, p.529-544, 1963b.

BERNARDES, Nilo. O espaço econômico brasileiro. Rio de Janeiro: Colégio Pedro II, 1966.

BERNARDES, Nilo. Condições geográficas da colonização em Alagoas. Revista Brasileira de Geografia, Rio de Janeiro. v.29, n.2, p.65-83, 1967.

BERNARDES, Nilo. Geografia e desenvolvimento. Boletim Geográfico, Rio de Janeiro. v.28, n.211, p.107-112, 1969a.

BERNARDES, Nilo. A geografia e o planejamento regional. São Paulo, 1969b.

BERNARDES, Nilo. Sobre diversificação e sua medida aplicada à geografia agrária. Geografia. Rio Claro, v.3, n.5, p.15-29, 1978.

BERNARDES, Nilo. O pensamento geográfico tradicional. Revista Brasileira de Geografia, Rio de Janeiro. v.44, n.3, p.391-413, 1982a. 
BERNARDES, Nilo. A influência estrangeira no desenvolvimento da Geografia no Brasil. Revista Brasileira de Geografia, Rio de Janeiro. v.44, n.3, p.519$527,1982 b$.

BERNARDES, Nilo. Bases geográficas do povoamento do Estado do Rio Grande do Sul. Ijuí: Ed. Unijui, 1997.

BERNARDES, Nilo. As caatingas. Estudos Avançados, São Paulo. v.13, n.35, p.69-78, 1999.

BERNARDES, Nilo (Org.). Minas Gerais: terra e povo. 2.ed. Porto Alegre: Globo, 1970.

BERNARDES, Lysia Maria Cavalcanti \& BERNARDES, Nilo. A pesca no litoral do Rio de Janeiro. Revista Brasileira de Geografia, Rio de Janeiro. v. 12, n.1, p.17-53, 1950.

CORRÊA, Roberto Lobato. Entrevistas e depoimentos. Geosul, Florianópolis. v.2, p.125-143,1986.

ETGES, Virgínia Elisabeta. Geografia agrária: a contribuição de Leo Waibel. Santa Cruz do Sul, EDUNISC, 2000.

FAUCHER, Daniel. Reflexões sobre o método em geografia agrária. Boletim Geográfico, Rio de Janeiro. v.21, n.173, p.185-188, 1963.

FERREIRA, Darlene Aparecida de Oliveira. Geografia Agrária no Brasil: conceituação e periodização. Terra Livre, São Paulo, n.16, p. 39-70, 2001.

HAESBAERT, Rogério. Vidal e a multiplicidade de abordagens regionais. p.185-201. In: HAESBAERT, Rogério; PEREIRA, Sérgio Nunes; RIBEIRO, 
Guilherme (Orgs). Vidal, Vidais: textos de geografia humana, regional e política. Rio de Janeiro: Bertrand Brasil, 2012.

HISSA, Cássio Eduardo Viana. Sobre pensamentos de Paul Vidal de La Blache: Reflexões sob a referência do presente. Geografia. Rio Claro. v.30, n.1, p.5-20, 2005.

MESQUITA, Zilá. Divisões regionais do Rio Grande do Sul: uma revisão. Ensaios FEE, Porto Alegre. v.5, n.2, p.95-146, 1984.

SCARIM, Paulo Cesar. A construção da geografia acadêmica no Brasil. In: Boletim Paulista de Geografia, São Paulo. n.88, p.41-71, 2008.

SUZUKI, Julio César. Geografia agrária: gênese e diversidade. In: MARAFON, Glaucio José; RUA, João; RIBEIRO, Miguel Ângelo. (Org.). Abordagens teórico-metodológicas em geografia agrária. Rio de Janeiro: Eduerj, 2007. p. 17-39.

VIDAL DE LA BLACHE, Paul. Princípios de geografia humana. 2.ed. Lisboa:Cosmos, 1954. 